\title{
Development of Hybrid Fischer-Tropsch Synthesis Catalysts for Direct Production of Synthetic Gasoline from Coal-Based Syngas: An Indonesian Perspective
}

\author{
Donny Bhuana ${ }^{1,2}$, Junshe Zhang ${ }^{2}$, Fanxing $\mathrm{Li}^{2}$, Matthew Cooper ${ }^{2} \&$ Timothy Brantley ${ }^{2}$ \\ ${ }^{1}$ Department of Chemical Engineering, Sepuluh Nopember Institute of Technology, Indonesia \\ ${ }^{2}$ Department of Chemical and Biomolecular Engineering, North Carolina State University, United States \\ Correspondence: Donny Bhuana, Department of Chemical Engineering, Sepuluh Nopember Institute of \\ Technology, Surabaya, 60111, Indonesia. E-mail: dsbhuana@ncsu.edu
}

Received: May 4, 2015

doi:10.5539/mas.v9n7p48
Accepted: June 5, 2015

Online Published: June 30, 2015

URL: http://dx.doi.org/10.5539/mas.v9n7p48

\begin{abstract}
The Fischer-Tropsch Synthesis (FTS) represents an environmentally friendly method for producing liquid fuel from coal-based syngas via the hydrogenation of carbon monoxide. In order for such a process to be feasible, better catalysts that are capable of enhancing the reaction performance are required. In response to these needs, new catalysts were investigated and introduced in this work. The incorporation of zeolite into the iron based FTS catalyst was expected to help refine the hydrocarbon products and shift the product distribution from the typical FTS product range to the middle iso-paraffins, which is a gasoline range, and eventually increase the yield of the liquid fuel. This study aims to develop catalyst for producing liquid fuel, particularly gasoline, from carbon monoxide and hydrogen. The $\mathrm{pH}$ of the catalysts was found to have significant effect on the catalytic activity due to its ability to control the amount of promoter to be precipitated in the catalyst, which results in a lower reduction temperature. Physically mixing the iron based FTS catalyst with zeolite was found to have little effect on the catalytic activity and the product distribution, apart from slightly increasing the selectivity of iso-paraffins, which is the indication of isomerization activity. Coating of zeolite onto the iron based FTS catalyst to form a core-shell structure was intended to enhance the ease of migration of the reactant and thus increasing the catalytic activity and shifting the product distribution towards the gasoline range. While zeolite shell has been successfully coated uniformly on the iron based core using hydrothermal synthesis technique, the formation of thick zeolite shell might have blocked the active FTS sites on the iron based catalyst to some extent and is believed to have contributed to the low activity of the core-shell catalyst.
\end{abstract}

Keywords: fischer-tropsch synthesis, catalyst, gasoline, coal, Indonesia

\section{Introduction}

Despite the fact that it only ranks fifteenth in the world in terms of recoverable coal reserves, surprisingly enough, Indonesia in fact has been one of the world's largest coal producers for years. This clearly indicates that only limited amount of the country's coal reserves have been utilized for domestic use, which gives rise to a promising future for the utilization of Indonesia's abundant coal reserves for direct conversion into synthetic fuels. Furthermore, with the ever increasing trend of the country's oil price within the last two decades, that has subsequently led to the increase of the food prices, the option of utilizing alternative forms of fuel to replace fossil fuels has become increasingly inevitable. In addition, according to the data from the BPH Migas in 2014, $67 \%$ of fuel used for transportation in Indonesia is from gasoline, while diesel consumption for transportation is in the second place with only $29 \%$ of the total fuel consumed. Therefore, there is a growing need to independently convert gasoline from natural gas/coal -derived syngas. This study aims to develop catalyst for producing liquid fuel, particularly gasoline, from syngas.

Fischer-Tropsch synthesis is an old technology to convert syngas into synthetic fuels, with metal oxides as a catalyst. Syngas from typical Indonesian sub-bituminous coal has a $\mathrm{H}_{2} / \mathrm{CO}$ ratio of 1.0 to 1.5 (Silaen et al., 2010), which is lower than the stoichiometric value of about 2.0. Based on this value, a number of FTS catalytic tests were carried out in this study. New catalysts were investigated and introduced in this work as well. The basic idea is to incorporate a RWGS (reversed water gas shift) and FTS bi-functional catalyst into a shell that is both 
active for RWGS and isomerization / hydrocracking. Iron was used as the main FTS catalyst due to its high WGS (water gas shift) activity, thus, effective to be used with CO-rich syngas. By combining the catalysts, promoters, and supports of the Fischer-Tropsch and the water gas shift reactions, it is expected that the catalysts activity will increase and thus, increasing the selectivity of the longer chained hydrocarbon produced and eventually increase the yield of the liquid fuel accordingly. The incorporation of zeolite into the iron based FTS catalyst will help refine the produced hydrocarbons and shift the product distribution from the typical FTS product range to the middle iso-paraffins, which are gasoline range hydrocarbons. Coating of zeolite onto the iron based FTS catalyst to form a core-shell structure was expected to enhance the ease of movement of the reactant gases, which in the end would be able to shift the product distribution to the gasoline range.

Converting the Fischer-Tropsch hydrocarbon into synthetic gasoline requires further refining of the FT products, such as hydrocracking and isomerization. These processes are considered to be complicated with the F-T step being prone to having catalyst deactivation issue due to the wax deposition on the catalyst surface. Therefore, carrying out the processes in one step would be beneficial to avoid catalyst deactivation problem, and in this case, designing a multifunctional catalyst for direct conversion of iso-paraffin from syngas would be advantageous. A number of efforts have been put to combine the Fischer-Tropsch hydrogenation catalysts with those for refinery processes. The concept of physically mixing the conventional FT catalysts and zeolite has been previously studied. Yoneyama and co-workers conducted a study on hybrid catalyst of iron and zeolite by physically mixing varied amount of zeolite and iron catalyst to accommodate direct synthesis of iso-paraffin from syngas. (Yoneyama et al., 2005). Despite showing no significant difference in terms of the catalytic activity, the study suggests that in general with traditional Fischer-Tropsch iron catalyst, the FTS products contain heavy normal paraffin from $\mathrm{C} 1$ to $\mathrm{C} 16$. However, after the addition of zeolite by physical mixing, the heavy normal paraffins disappeared and the product distribution shifted towards the formation of lighter chained hydrocarbons, i.e. C1-C10 that are rich in iso-paraffins. (Li et al., 2003).

Fischer-Tropsch based fuels are only suitable to be used as synthetic diesel fuel due to the presence of normal paraffin comprising the fuels. Additional processes such as hydrocracking and isomerization are required to convert the linear paraffins into branched paraffins in order to produce synthetic gasoline. While physically mixing the Fischer-Tropsch catalyst with that of hydrocracking and isomerization can actually suppress the formation of longer chained hydrocarbon as well as increase the selectivity of branched paraffins to some extent, the performance can still be improved. For the iron-zeolite dry mixed catalysts, the active sites are distributed in random locations on the catalyst surface, which results in unrestricted reaction sites that allow both FTS reaction and hydrocracking \& isomerization reaction to occur randomly and independently. This suggests that there is a chance for the FTS products to leave the catalyst surface directly without further reacting with the active sites of zeolite. The ease of migration and mobility of the FTS products appears to play important roles in determining the successful formation of middle iso-paraffin hydrocarbons. To foster this concept, a novel multifunctional catalyst with core shell structure has been introduced. (Bao et al., 2008). The core part consists of conventional FTS catalysts while the shell comprises a layer of H-type zeolite enwrapping the core. The syngas passes through the shell to reach the core catalyst and eventually undergo FTS reaction to form linear paraffins. Prior to leaving the catalysts, all the linear paraffins must first pass through the zeolite shell and that is where hydrocracking and isomerization reactions take place and the linear paraffins have a better chance of getting converted into iso-paraffins on the acidic sites of zeolite. Owing to its ability to improve the collision possibility between linear paraffins and zeolite acidic sites, the core shell catalyst is expected to give higher selectivity towards iso-paraffins compared to the physically mixed catalyst.

\section{Method}

\subsection{Synthesis of Core Materials}

Iron-based catalysts were synthesized using co-precipitation method. Silica and alumina was used as structural promoters, respectively, while potassium was used as a chemical promoter. Fe-based core materials have been prepared according to $100 \mathrm{Fe} / 25 \mathrm{SiO}_{2} / 5 \mathrm{Cu} / 4.2 \mathrm{~K}$ (mass basis). $\mathrm{Fe}\left(\mathrm{NO}_{3}\right)_{3} \cdot 9 \mathrm{H}_{2} \mathrm{O}$ and $\mathrm{Cu}\left(\mathrm{NO}_{3}\right)_{2} \bullet 6 \mathrm{H}_{2} \mathrm{O}$ were dissolved in de-ionized water (D.I. water), followed by heating the solution up to $80^{\circ} \mathrm{C}$ on a hotplate. A $10 \mathrm{wt} \%$ $\mathrm{NH}_{4} \mathrm{OH}$ base solution was added to the nitrate solution under vigorous stirring. The suspension was kept at $80^{\circ} \mathrm{C}$ under stirring for $1 \mathrm{~h}$ after adding the base solution and then it cooled down to room temperature naturally. The precipitate was aged for 1 day under ambient conditions, followed by filtering and washing it thoroughly with D.I. water. Subsequently, $\mathrm{K}_{2} \mathrm{SO}_{3}$ solution was added to the wet precipitate and the $\mathrm{pH}$ of suspension was adjusted to below 6 at room temperature. The suspension was then kept at ambient conditions for 2 days before being filtered and the wet cake being washed with D.I. water. Finally, the solid product was dried at $120{ }^{\circ} \mathrm{C}$ in an oven overnight. Potassium was introduced to the resulted solid by the wet incipient impregnation, with $\mathrm{KNO}_{3}$ solution 
as a precursor.

\subsection{Synthesis of Core-Shell Catalysts}

D.I. water, ethanol, tetraethyl orthosilicate (TEOS), tetrapropylammonium hydroxide (TPAOH) were mixed in a Teflon container. Iron-based core materials was added to the above solution under vigorous agitation before adding $\mathrm{Al}\left(\mathrm{NO}_{3}\right)_{3} \cdot 9 \mathrm{H}_{2} \mathrm{O}$ to the suspension, and followed by stirring under ambient conditions. Finally, the Teflon container was capped and then put into a stainless steel hydrothermal reactor, which was kept at $180{ }^{\circ} \mathrm{C}$ for 2 days in an oven. Upon the completion of hydrothermal reaction, the solid product was recovered by filtration and washed by D. I. water. The solid product was dried $120^{\circ} \mathrm{C}$ for $20 \mathrm{~h}$ in an oven and finally calcined at $500^{\circ} \mathrm{C}$ for 5 $\mathrm{h}$ in open air.

\subsection{Characterization}

The morphology of core materials and core-shell catalysts was investigated with a Hitachi S-3200N VP-SEM. Elemental analysis was carried out to estimate the surface composition and distribution of each element on the cross sectional surface of solids. Powder XRD measurements were carried out on a Bragg-Brentano X-Ray Diffractometer-Rigaku SmartLab. The patterns were acquired in a $2 \theta$ range of 10 to $80^{\circ}$ at a scan rate of $2^{\circ} / \mathrm{min}$, a step size of $0.02^{\circ}$. The tube current was $44 \mathrm{~mA}$ with a tube voltage of $40 \mathrm{kV}$ CuThe phases were identified by comparing the collected diffraction patterns with those compiled on the database. $\mathrm{H}_{2}-\mathrm{TPR}$ was performed on a ChemBET Pulsar TPR/TPD hemisorptions analyzer.

\subsection{Catalytic Test}

Figure 1 shows the diagram of the Fischer-Tropsch Synthesis system. Reactant gases, such as $\mathrm{CO}, \mathrm{H}_{2}$, and $\mathrm{N}_{2}$ enter the reactor from the gas-mixing panel attached on the supporting box. The reactor and both condensers are equipped with heat tracings to maintain the desired temperature level, with heating tapes being used in the reactor and the hot trap, and a cooling coil with refrigerant for the cold trap. Mass flow controllers are used to control the flow of the gases. In order to determine the performance of different types of catalysts, a catalyst-inert mixture with 1:2 ratio is introduced to the fixed bed reactor to undergo Fischer-Tropsch Synthesis reaction over a certain period of time. The resulting wax and liquid products are periodically drained from the hot trap and cold trap condensers, respectively. The outlet gases line is connected to a gas chromatography (GC, Agilent CP-490 Micro-GC) instrument that allows direct measurement of the gaseous product composition. The Micro GC instrument is equipped with a Thermal Conductivity Detector (TCD) and four sampling columns, including two Molsieve 10A, Pora Plot U, and CP-Sil 5 CB, with Argon and Helium as carrier gases. The apparatus also has a bypass line connected to it that allows unreacted gases to go to the GC instrument for inspection purpose.

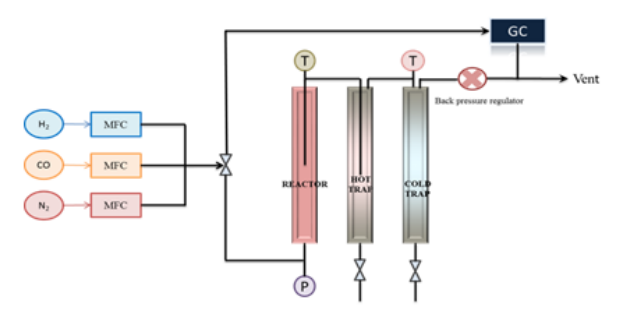

Figure 1. Simplified diagram of FTS reactor system

\section{Results}

\subsection{Characterization of Core Materials}

The activation procedure has a strong influence on the activity and selectivity. In order to gain fundamental insights into the activation process, $\mathrm{H}_{2}-\mathrm{TPR}$ on three $\mathrm{Fe} / \mathrm{Al} / \mathrm{Cu} / \mathrm{K}$ catalysts were performed and the results are presented on Figure 2(a). As the temperature ramps up from 100 to $1000^{\circ} \mathrm{C}$, iron oxides are reduced to magnetite $\left(\mathrm{Fe}_{3} \mathrm{O}_{4}\right)$ and $\alpha-\mathrm{Fe}$, corresponding to two main peaks on the TPR curves, the first one was located between 300 and $500^{\circ} \mathrm{C}$ and the other centered around $590^{\circ} \mathrm{C}$, as shown on Figure 2(b). Our findings suggest that the pH at which the precipitate was aged significantly affects the reduction behavior, as the $\mathrm{pH}$ increase from 4.75 to 6.98 , the low temperature peak shifts from 407 to $342^{\circ} \mathrm{C}$. As the $\mathrm{pH}$ increases, more copper will precipitate from the solution, resulting in a higher $\mathrm{Cu}$ content. The TPR analysis was carried out in a hydrogen atmosphere. Even though the reduction behaviors of $\mathrm{Fe} / \mathrm{Al} / \mathrm{Cu} / \mathrm{K}$ in $\mathrm{H}_{2}$ atmosphere was not particularly investigated, we believe the information obtained from the $\mathrm{H}_{2}$-based TPR is sufficiently accurate for $\mathrm{CO}$ activation as well. Previous studies 
suggest that activation under $\mathrm{CO}$ yields the best performance in terms of syngas conversion and methane selectivity compared to those activated with hydrogen or syngas. [van de Loosdrecht, 2013]. In addition, the final catalyst exhibit a relative high WGS activity. This is very effective for typical Indonesian coal-derived syngas, which has a low $\mathrm{H}_{2} / \mathrm{CO}$ ratio.
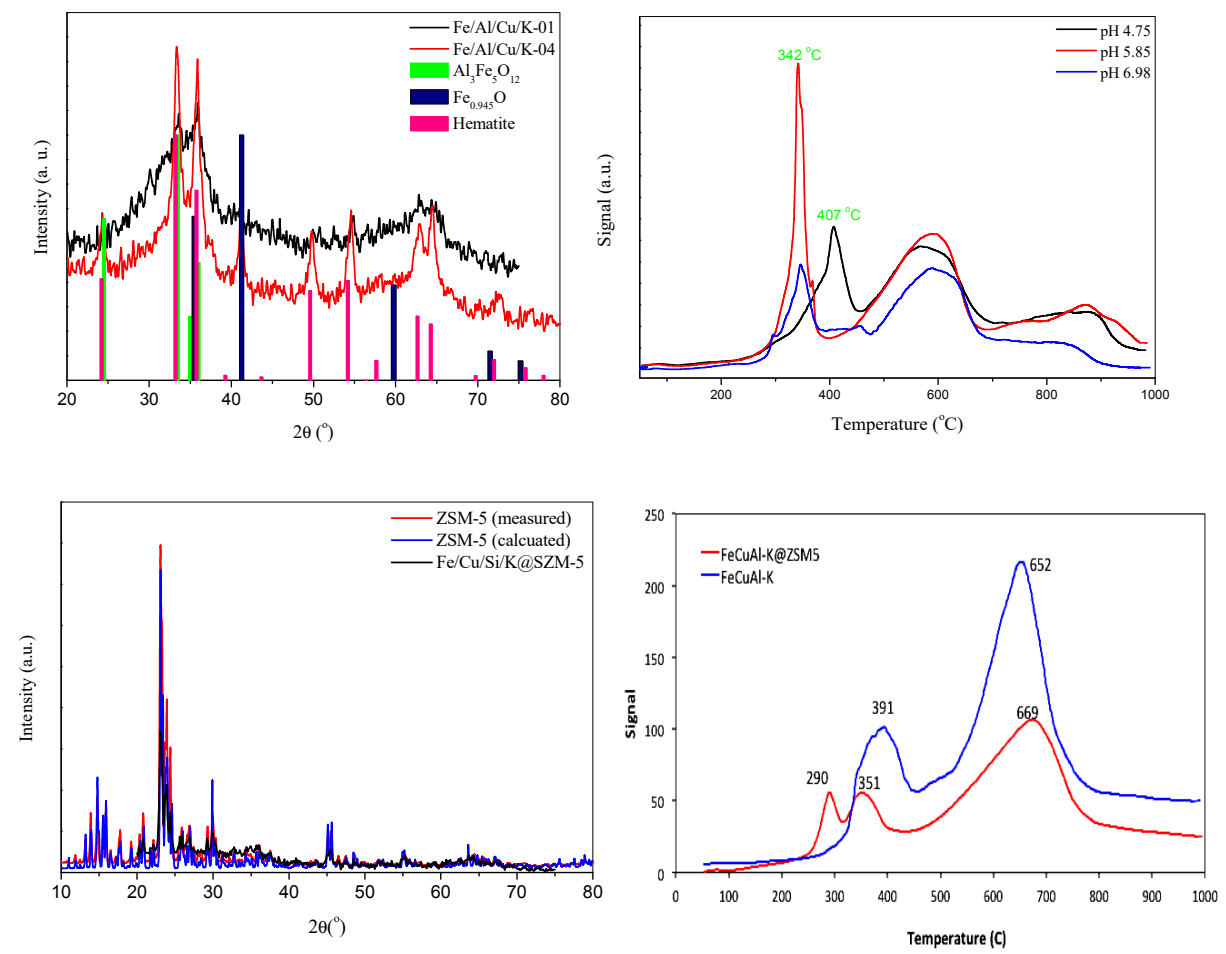

Figure 2. (a) XRD patterns of FeCuAl-K core catalysts (b) $\mathrm{H}_{2}$-TPR profiles of three Fe-based core catalysts (c) XRD patterns of ZSM-5 and Fe/Si/Cu/K@ZSM-5 core-shell catalysts (d) $\mathrm{H}_{2}$-TPR profiles for FeCuAl-K (core) \&FeCuAl-K@ZSM5 (core-shell)
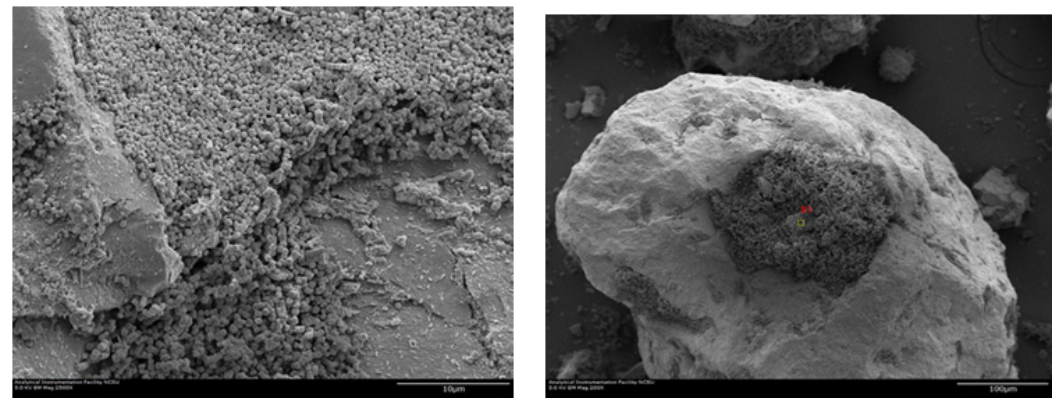

Figure 3. SEM images for Fe/Si/Cu/K@ZSM5 and Fe/Al/Cu/K@ZSM5

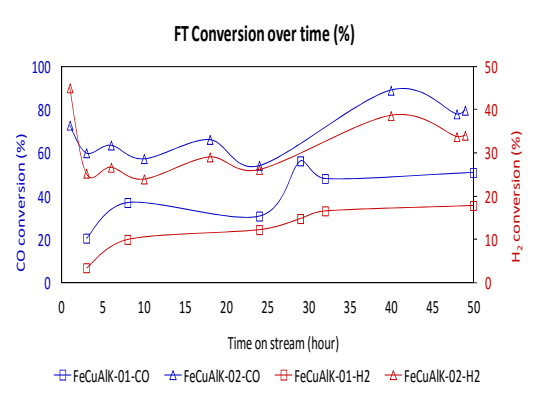

Figure 4. Conversion of $\mathrm{CO}$ and $\mathrm{H} 2$ over $\mathrm{Fe} / \mathrm{Cu} / \mathrm{Al} / \mathrm{K}$ catalysts.

Reaction conditions: $\mathrm{T}=270 \mathrm{oC}, \mathrm{P}=$ $120 \mathrm{psi}, \mathrm{H} 2 / \mathrm{CO}=2$, GHSV=7,200 SCCM h-1 gcat.-1

For the combined FTS and upgrading process, a close interaction between the F-T catalysts and zeolite shell plays important role in determining the product selectivity. The zeolite shell is expected to uniformly grow around the core while the syngas, as reactant, diffuses through the zeolite shell to reach the core, where long-chain hydrocarbons are formed, and then all these species diffuse out through the zeolite shell, in which cracking and isomerization take place. Several SEM images, shown on Figure 3, have been acquired to verify the coating of zeolite shell on the core iron-based catalysts.The SEM images suggest that zeolite has been successfully grown on the surface of the core, however, as can be seen from the images, the core surface is only 
partially coated with a thin shell of zeolite even though in some area of the sample complete coverage of zeolite on the core can also be spotted.

\section{Discussion}

\subsection{CO Hydrogenation Over Core Materials}

The catalytic performance of the core materials during the $\mathrm{CO}$ hydrogenation was evaluated at temperatures less than $300^{\circ} \mathrm{C}$ in a continuous flow fixed-bed reactor. All the results presented in this paper were obtained based on particular experiments carried out at $270^{\circ} \mathrm{C}$. The conversions of $\mathrm{CO}$ and $\mathrm{H}_{2}$ as a function of time over the two different catalysts, i.e. $\mathrm{Fe} / \mathrm{Cu} / \mathrm{Al} / \mathrm{K}-01$ and $\mathrm{Fe} / \mathrm{Cu} / \mathrm{Al} / \mathrm{K}-02$, are shown on Figure 4. It should be noted that the only difference between these two catalysts is $\mathrm{pH}$ at which the precipitate aged, with the former having $\mathrm{pH}$ of 4.75 and the later being 5.85. As suggested from the figure, the F-T activity over core materials appears to be strongly dependent on $\mathrm{pH}$, in which both $\mathrm{CO}$ and $\mathrm{H}_{2}$ conversions of the $\mathrm{Fe} / \mathrm{Al} / \mathrm{Cu} / \mathrm{K}-02$ are significantly higher than those of $\mathrm{Fe} / \mathrm{Al} / \mathrm{Cu} / \mathrm{K}-01$. Furthermore, our findings suggest that the $\mathrm{pH}$ at which the precipitate was aged significantly affects the reduction behavior, in which a decrease in reduction temperature was observed with the increasing $\mathrm{pH}$ value. Furthermore, Figure 4 demonstrates that $\mathrm{CO}$ and $\mathrm{H}_{2}$ conversion over $\mathrm{Fe} / \mathrm{Al} / \mathrm{Cu} / \mathrm{K}-02$ decreases at the very early state of reaction (minimizes at $4 \mathrm{~h}$ ), and then goes back up to the initial values and then starts decreasing again as the reaction proceeds. The conversion decrease in the later stage of the reaction could be attributed to deactivation, possibly due to carbon deposition, transformation of active phases, mechanical break-up of catalysts, and sintering. Despite the more stable increase in the conversion of the $\mathrm{Fe} / \mathrm{Cu} / \mathrm{Al} / \mathrm{K}-01$, the $\mathrm{Fe} / \mathrm{Cu} / \mathrm{Al} / \mathrm{K}-02$ catalyst exhibits a higher overall conversion compared to its more acidic counterpart. Table 1 lists the average selectivity of $\mathrm{CO}_{2}, \mathrm{CH}_{4}$, oil and solid over two $\mathrm{Fe} / \mathrm{Al} / \mathrm{Cu} / \mathrm{K}$ catalysts at $270^{\circ} \mathrm{C}$ and $120 \mathrm{psi}$ at a $\mathrm{H}_{2}$ to $\mathrm{CO}$ ratio of 2.0. It appears that the synthesis conditions only have insignifiant effect on gas and liquid selectivity but strongly affect the wax selectivity. This might be attributed by the fact that the content of $\mathrm{Cu}$ could influence the chain growth probability $(\alpha)$ of heavy hydrocarbons.

Table 1. Product selectivity over $\mathrm{Fe} / \mathrm{Cu} / \mathrm{Al} / \mathrm{K}$ (reaction conditions: $T=270{ }^{\circ} \mathrm{C}, P=120 \mathrm{psi}, \mathrm{H}_{2} / \mathrm{CO}=2$, GHSV=7,200 SCCM h ${ }^{-1} \mathrm{~g}_{\text {cat. }}{ }^{-1}$ )

\begin{tabular}{lllll}
\hline Catalyst & $\mathrm{CO}_{2}$ & $\mathrm{CH}_{4}$ & $\mathrm{Oil}^{\mathrm{a}}$ & $\mathrm{Wax}^{\mathrm{a}}$ \\
\hline $\mathrm{Fe} / \mathrm{Al} / \mathrm{Cu} / \mathrm{K}-01$ & 28.44 & 1.47 & 6.82 & 1.44 \\
$\mathrm{Fe} / \mathrm{Al} / \mathrm{Cu} / \mathrm{K}-02$ & 30.05 & 1.63 & 8.71 & 15.16 \\
\hline
\end{tabular}

${ }^{\mathrm{a}}$ The amount of oil /wax collected from cold/hot trap in $24 \mathrm{~h}$.

The composition of the product was evaluated from the product distibution of oil product, as shown on Figure 5 (a). The product distribution is expected to follow the ASF distribution, however, $\mathrm{C}_{5}$ to $\mathrm{C}_{8}$ hydrocarbons appear lower than what they are supposed to be. This is attributed to the fact that a portion of these hydrocarbons were present in the gas phase inside the cold trap. Furthermore, the estimated $\alpha$ value from the molar fraction of hydrocarbons with carbon numbers of 9 to 15 was 0.87 , which is a typical one for LTFT synthesis. (van de Loosdrecht, 2013).
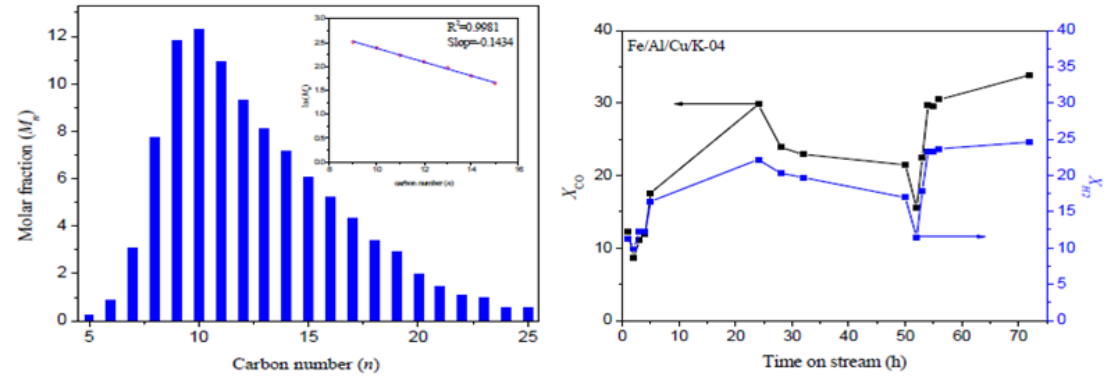

Figure 5. (a) Product distribution over $\mathrm{Fe} / \mathrm{Al} / \mathrm{Cu} / \mathrm{K}-02$ catalysts (b) Conversion of $\mathrm{CO}$ and $\mathrm{H}_{2}$ over

$\mathrm{Fe} / \mathrm{Si} / \mathrm{Cu} / \mathrm{K} @ \mathrm{ZSM}-5$ core-shell catalyst. Reaction conditions: $T=270^{\circ} \mathrm{C}, P=120 \mathrm{psi}, \mathrm{H}_{2} / \mathrm{CO}=2, \mathrm{GHSV}=7,200$ $\mathrm{SCCM} \mathrm{h} \mathrm{h}^{-1} \mathrm{~g}_{\text {cat. }}$

\subsection{CO Hydrogenation Over Core-Shell Catalysts}

As shown in Figure 5 (b), the conversion of $\mathrm{CO}$ and $\mathrm{H}_{2}$ appears increasing continuously over a reaction 
period of 24 hours. This could be attributed to the reconstruction or transformation among iron species under the reaction conditions. With the same amount of catalysts and reaction conditions, the core-shell catalyst exhibits lower conversion of $\mathrm{CO}$ and $\mathrm{H}_{2}$ compared to the lone core itself. This might be caused by the low activity of the ZSM-5 with respect to the FT synthesis, in addition to the possibility of the potassium promoter getting carried away during the hydrothermal synthesis procedure to coat the Fe-based core with the zeolite shell. The average selectivities of $\mathrm{CO}_{2}$, methane, and oil in $24 \mathrm{~h}$ are $7.55,2.31$, and $5.49 \%$, respectively. Compared with core materials, the low $\mathrm{CO}_{2}$ selectivity could be attributed to the loss of the potassium, which is an active water gas shift (WGS) promoter. One noticable observation is that no wax was collected from the hot trap after 24 hour-run, indicating that coating of the zeolite on the Fe-based core catalyst can suppress the formation of heavier hydrocarbons product.

A number of notable findings have been identified and highlighted during this study, such as the significant effect of $\mathrm{pH}$ on the catalytic activity due to its ability to control the amount of promoter to be precipitated in the catalyst, which results in a lower reduction temperature and eventually leads to a higher catalytic activity. Even though it has not been uniformly coated throughout the surface of the core catalyst, zeolite shell has been successfully grown on the iron-based core catalyst using hydrothermal synthesis technique. Both the iron-based core and the core-shell catalysts were catalytically tested using a laboratory-scale syngas whose $\mathrm{H}_{2} / \mathrm{CO}$ ratio represents the actual condition of that derived from typical Indonesian sub-bituminous coal. Lower catalytic performances were investigated on the core-shell catalyst in comparison with the core catalyst, with the low activity of ZSM-5 towards the FTS and the loss of some potassium during the zeolite coating procedure being some possible causes that contribute to the phenomena. A separate catalytic test on ZSM-5 will need to be carried out in the near future to determine its FTS activity in addition to improving zeolite coating procedure, such as introducing rotation/agitation to the reactor during the hydrothermal synthesis so that the surface of the core particle can be more thoroughly exposed to the solution.

\section{Acknowledgements}

This work has been financially supported by the Illinois Clean Coal Institute (ICCI), the Fulbright Foundation, and the Indonesian Directorate General of Higher Education (DIKTI).

\section{References}

Bao, J., He, J., Zhang, Y., Yoneyama, Y., \& Tsubaki, N. (2008). A Core/Shell Catalyst Produces a Spatially Confined Effect and Shape Selectivity in a Consecutive Reaction. Angewandte Chemie, 120, 359-362. http://dx.doi.org/10.1002/ange.200703335

Li, X., Asami, K., Luo, M., Michiki, K., Tsubaki, N., \& Fujimoto, K. (2003). Direct synthesis of middle

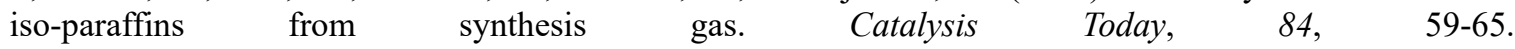
http://dx.doi.org/10.1016/S0920-5861(03)00301-8

Silaen, A., \& Wang, T. (2010). Investigation of the Coal Gasification Process under Various Operating Conditions inside a Two Stage Entrained Flow Gasifier, Proceeding of the 27th International Pittsburgh Coal Conference, Istanbul, Turkey, 11-14, 2010.

Supramono, D., Tristantini, D., Rahayu, A., Suwignjo, R. K., \& Chendra, D. H. (2014). Syngas Production from Lignite Coal Using $\mathrm{K}_{2} \mathrm{CO}_{3}$ Catalytic Steam Gasification with Controlled Heating Rate in Pyrolysis Step. Prodia Chemistry, 9, 202-209. http://dx.doi.org/10.1016/j.proche.2014.05.024

Van de Loosdrecht, J., Botes, F. G., Ciobica, I. M., Ferreira, A., Gibson, P., Moodley, D. J., Siab, A. M., Visagie, J. L., Weststrate, C. J., \& Niemantsverdriet, J. W. (2013). Comprehensive Inorganic Chemistry II, Elsevier: Amsterdam, 7, 525 -557.

Yoneyama, Y., He, J., Morii, Y., Azuma, S., \& Tsubaki, N. (2005). Direct synthesis of isoparaffin by modified Fischer-Tropsch synthesis using hybrid catalyst of iron catalyst and zeolite. Catalyst Today, 104, 37-40. http://dx.doi.org/10.1016/j.cattod.2005.03.031

Zhang, Q., Kang, J., \& Wang, Y. (2010). Development of Novel Catalysts for Fischer-Tropsch Synthesis: Tuning the Product Selectivity. ChemCatChem, 2, 1030-1058. http://dx.doi.org/10.1002/cctc.201000071

\section{Copyrights}

Copyright for this article is retained by the author(s), with first publication rights granted to the journal.

This is an open-access article distributed under the terms and conditions of the Creative Commons Attribution license (http://creativecommons.org/licenses/by/3.0/). 